\begin{tabular}{|c|c|}
\hline JURNAL EKONOMI DAN MANAJEMEN \\
P-ISSN: 2598-9022/ E-ISSN: 2598-9618 \\
Available at: http://e- \\
journal.unipma.ac.id/index.php/capital
\end{tabular}

\title{
Peluang Revolusi Industri 4.0 Bidang Pemasaran: Pemanfaatan Aplikasi $E$ - commerce, Sosial Media Instagram dan Digital Marketing terhadap keputusan Instant Online Buying Konsumen Generasi Millenial.
}

\author{
Bambang Setia Wibowo $^{1)}$, Diaz Haryokusumo ${ }^{2)}$ \\ ${ }^{1}$ STIE YKPN Yogyakarta \\ bambang.setia@ @tieykpn.ac.id \\ ${ }^{2}$ STIE YKPN Yogyakarta \\ diaz@stieykpn.ac.id
}

\begin{abstract}
This study examined the influence of e-commerce application, social media instagram and digital marketing to online purchases of millennial generation consumers. Respondents of this study were 152 university students who have already shopped online at e-commerce applications, have ever seen ecommerce advertisements on electronic media and have used social media instagram for online shopping participated in this reseach. There are several findings in this study. First, e-commerce application has positive influence to online purchases of millennial generation consumers. Second, social media instagram has postive effect to online purchases of millennial generation consumers. Third, digital marketing has positive effect to online purchases of millennial generation consumers.
\end{abstract}

Keywords : industrial revolution 4.0, e-commerce, instagram, digital marketing, instant online buying, millennial generation consumers

\section{A. PENDAHULUAN}

Teknologi baru dengan memanfaatkan internet menjadi titik strategis pada proses revolusi industri saat ini. Revolusi industri 4.0 merupakan integrasi pemanfaatan internet dengan lini produksi di dunia industri. Perubahan pun terjadi dalam dunia industri dewasa ini yang ditandai berubahnya iklim bisnis dan industri yang semakin kompetitif karena perkembangan teknologi informasi. Industri 4.0 merupakan industri yang menggabungkan teknologi otomatisasi dengan teknologi cyber. Hal ini meliputi tren otomatisasi dan pertukaran data dalam teknologi bisnis yang mencakup beberapa bagian yaitu Internet of Things (IoT), komputasi awan dan komputasi kognitif.

Tren belanja online dan digital marketing menjadi peluang produsen untuk menyambut era revolusi industri 4.0. Online shopping atau aktivitas berbelanja online menjadi gaya hidup baru bagi pengguna Internet. Komunikasi terbuka yang sejajar, datar, dan luas telah membuka kemungkinan tidak terbatas bagi komunikasi antar pengguna Internet, yang pada akhirnya juga membuka peluang bagi terjadinya transaksi menjual atau membeli. Platform atau forum jual beli channel yang paling sering 
digunakan terutama bagi pengguna internet laki-laki untuk belanja online. Sementara pengguna internet perempuan lebih cenderung memilih situs jejaring sosial yaitu sebesar 50,6\%, dan 24\% laki-laki (Hausman dan Siekpe, 2009). Internet menunjukkan berbagai segi fungsi pemasaran, bekerja sebagai sebuah mekanisme untuk membangun permintaan, mengarahkan konsumen ke aksi pembelian, mengisi pesanan, menyediakan layanan pelanggan, dan juga berfungsi sebagai media periklanan yang serba guna. Internet diklaim sebagai media komunikasi yang lebih baik karena keserbagunaannya dan superioritasnya dalam menargetkan konsumen (Maoyan et al., 2014).

Penelitian ini akan membahas lebih lanjut mengenai media sosial instagram. instagram adalah aplikasi gratis untuk berbagi foto yang memungkinkan penggunanya untuk mengambil foto dan selanjutnya berbagi pada layanan jejaring sosial (Zadmehr et al., 2016). Instagram dapat terhubung langsung ke media sosial lainnya seperti facebook dan twitter. Di dalam instagram, pengguna dapat memberikan tanda like dengan simbol love dan juga memberikan komentar terhadap foto dan video yang diunggah sendiri atau foto dan video yang diunggah pengguna instagram lain.

Program periklanan yang tepat harus ditunjang dengan efektivitas iklan yang baik pula. Efektivitas iklan tidak terbatas hanya untuk pembelian produk melainkan diperluas ke berbagai aspek psikologis dan kognitif yang berkaitan dengan kesadaran dan niat yang memainkan peran penting dalam keputusan pembelian (Ramalingam et al., 2006). Oleh sebab itu, orientasi efektivitas iklan tidak hanya terhadap niat pembelian produk tersebut tetapi tentang hubungan jangka panjang antara kebutuhan konsumen dan produk yang diiklankan.

Shah et al. (2011) menunjukkan bahwa perilaku pembelian konsumen berlangsung dengan stimulasi pelanggan dengan faktor internal dan eksternal (seperti memilih produk, merek, pengecer, waktu, dan kuantitas), dan konsumen membuat keputusan pembelian berdasarkan kualitas individu mereka, kepribadian, karakteristik dan proses pengambilan keputusan. Ini berarti bahwa pilihan konsumen terhadap produk dan merek berdampak pada perilaku pembelian mereka.

Penelitian ini bertujuan untuk menguji pengaruh pemanfaatan aplikasi $e$ commerce, sosial media instagram dan digital marketing terhadap instant online buying konsumen generasi millenial. Berdasarkan hal tersebut diharapkan akan memberikan 
gambaran peluang revolusi industri 4.0 ditinjau dari digital marketing dan instant online buying konsumen generasi millenial.

\section{B. TINJAUAN PUSTAKA}

Iklan adalah bentuk promosi dan promosi merupakan salah satu elemen yang paling penting dari bauran pemasaran. Tujuan dari iklan adalah untuk mempertahankan proses komunikasi dengan pelanggan, di mana pelanggan mendapatkan informasi tentang produk, karakteristik, harga dan syarat penjualan. Saat ini promosi melalui internet sangat membantu dan memang perlu untuk menggunakan alat-alat dan inovasi yang tersedia untuk dapat dengan benar menerapkan layanan promosi yang pada akhirnya akan berujung pada keberhasilan bisnis. Tiago dan Verissimo (2002) menetapkan empat dimensi Digital Marketing. Empat dimensi tersebut yang dikenal sebagai berikut: Interactive, Incentive Program, Site Design, Cost.

Perkembangan teknologi informasi sangat berkembang pesat. Berbagai kegiatan bisnis kecil sampai besar memanfaatkan perkembangan ini untuk menjalankan usahanya. Banyaknya competitor menjadi pertimbangan bagi para pengusaha untuk masuk dalam persaingan yang sangat ketat. Strategi pemasaran dan media yang tepat digunakan untuk bisa meraih pasar yang dituju sehingga volume penjualan selalu meningkat dan profit. Digital Marketing menurut Taken (2014) adalah salah satu media pemasaran yang saat ini sedang banyak diminati oleh masyarakat untuk medukung berbagai kegiatan yang dilakukan. Mereka sedikit demi sedikit mulai meninggalkan model pemasaran konvesional/tradisional beralih ke pemasaran modern yaitu digital marketing. Dengan digital marketing komunikasi dan transaksi dapat dilakukan setiap waktu/real time dan bisa mengglobal atau mendunia. Dengan jumlah pengguna sosial media berbasis chat ini yang banyak dan semakin hari semakin bertambah membuka peluang bagi UKM untuk mengembangkan pasarnya dalam genggaman smartphone (Huang dan Benyoucef, 2013).

Perdagangan elektronik (e-commerce) menurut Laudon (2012) adalah the use of internetandthe web to transact business, dapat disimpulkan bahwa e-commerce adalah melakukan perdagangan atau transaksi bisnis secara online dengan menggunakan media internet dan perangkat-perangkat online lainnya. E-commerce (EC) membantu melakukan perdagangan tradisional melalui cara-cara baru mentransfer dan memproses 
informasi, karena informasi inti dari semua kegiatan komersial. E-commerce mengacu pada pertukaran informasi bisnis menggunakan pertukaran data elektronik, surat elektronik, electronic bulletin board, transfer dana elektronik dan teknologi berbasis jaringan lainnya. Informasi secara elektronik ditransfer dari komputer ke komputer dengan cara otomatis.

Laudon (2012) membagi perdagangan elektronik (e-commerce) menjadi lima jenis, yaitu:

1. Business-to-Consumer (B2C) E-commerce.

2. Business-to-Business (B2B) E-commerce.

3. Consumer-to-Consumer $(C 2 C)$ E-commerce.

4. Peer-to-Peer $(P 2 P)$ E-commerce.

5. Mobile Commerce (M-commerce).

Penelitian ini lebih memfokuskan kepada Consumer-to-Consumer (C2C) ECommerce. C2C E-Commerce adalah jenis e-commerce yang memberikan wadah kepada konsumen untuk melakukan jual beli dengan konsumen lain secara online (Laudon, 2012), tujuan dari c2c e-commerce sendiri adalah untuk memudahkan penjual dan pembeli. Kebanyakan dari c2c e-commerce yang didirikan memberikan layanan gratis penggunaan kepada konsumennya, c2c e-commerce sendiri hanya bertindak sebagai pihak ketiga. Di Indonesia c2c e-commerce lebih dikenal dengan sebutan situs jual beli online, contohnya adalah berniaga.com, olx.co.id, tokopedia.com, elevania.com dan bukalapak.com.

Belanja online didefinisikan sebagai perilaku mengunjungi toko online melalui media internet untuk mencari, menawar atau membeli produk dengan niat membeli dan mendapatkan produk tersebut. Di Indonesia masih terdapat banyak toko online, dimana transaksi pembayaran masih dilakukan dengan cara nononline, seperti transfer antar bank (Amelina dan Zhu, 2016). Belanja online atau online shopping ini sangat diminati berbagai kalangan karena mempermudah manusia untuk berbelanja kapanpun dan dimanapun tanpa harus pergi ke pusat perbelanjaan. Ragam barang dan jasa yang ditawarkan dalam online shop pun lengkap layaknya toko atau pusat perbelanjaan yang nyata (Che et al., 2017).

Online shopping atau belanja online via internet, adalah suatu proses pembelian barang atau jasa melalui internet. Sejak kehadiran internet, para pedagang telah 
berusaha membuat toko online dan menjual produk kepada mereka yang sering menjelajahi dunia maya (internet) melalui berbagai macam media sosial, blog, bahkan web (Alharethi, 2016). Berbisnis melalui internet memberikan kemudahan tersendiri bagi penjual maupun pembeli, selain efisien dalam biaya iklan juga efektif dalam promosi karena masyarakat saat ini banyak mengandalkan online shop untuk berbelanja.

Berbelanja juga dipengaruhi oleh banyak faktor. Faktor yang mempengaruhi perilaku membeli menurut (Kotler, 2009) terdiri dari: 1. Kebudayaan yang terdiri dari: budaya, sub budaya dan kelas sosial. 2. Sosial yang terdiri dari: kelompok acuan, keluarga, peran dan status. 3. Personal yang terdiri dari: usia dan siklus hidup, pekerjaan, keadaan ekonomi, gaya hidup, kepribadian, dan konsep diri. 4. Psikologi yang terdiri dari: motivasi, persepsi, proses belajar, proses belajar, kepercayaan dan sikap. Beberapa faktor tersebut dapat mempengaruhi calon pembeli dalam berbelanja baik secara langsung maupun tak langsung.

Efisiensi kualitas pelayanan digunakan untuk mengukur keunggulan dan ketepatan layanan yang diterima oleh pelanggan online. Studi sebelumnya telah menyatakan bahwa kegunaan pendapat yang dirasakan oleh konsumen terkait dengan kualitas layanan online merupakan bukti pentingnya pelayanan online yang diberikan menurut Zeithamlet al(2002).

Chen dan Dubinsky(2003) menyatakan persepsi konsumen terhadap kualitas keseluruhan dari suatu produk atau jasa pada e-commerce dapat menentukan nilai dari produk atau jasa tersebut dan berpengaruh secara langsung kepada keputusan pembelian konsumen dan loyalitas mereka terhadap merek. Berdasarkan penjelasan tersebut maka hipotesis pertama yang diajukan adalah:

\section{H1: Pemanfaatan Aplikasi E-commerce berpengaruh positif terhadap Instant Online Buying Konsumen.}

Instagram Online Store berpengaruh terhadap keputusan pembelian (Che et al., 2017). Pelaku bisnis online mengaku lebih mudah memasarkan produknya melalui Instagram karena sasaran pertama adalah orang yang paling dekat dengannya, bisa juga melalui teman yang awalnya dari mulut ke mulut sambil menunjukan akun Instagram, komunikasi tersebut sangat efektif bagi para penjual, dengan adanya media Instagram semakin mudahnya penjual menunjukkan foto atau katalaog barang jualannya. Dalam 
hal ini secara tidak langsung proses tersebut membentuk suatu rangkaian komunikasi pemasaran dan menimbulkan perilaku konsumtif untuk berbelanja (Alharethi, 2016).

Tarasova (2015) mengemukakan kelebihan spesifik online shop menggunakan media Instagram adalah pasar yang melek teknologi. Salah satu kelebihan berjualan lewat Instagram adalah pengguna Instagram sudah melek teknologi. Artinya, mereka yang aktif di Instagram pastilah aktif pula di Twitter dan mungkin juga Facebook. Oleh karena itu, sangat tepat bila mempromosikan produk melalui Instagram dan dibantu jejaring sosial lainnya, pengguna Instagram pastilah memiliki gadget dan smartphone mahal yang mendukung aplikasi tersebut seperti iPhone, ini berarti Instagram memiliki pengguna yang rata-rata kelas menengah ke atas. Hal ini menguntungkan bagi penjual, karena calon konsumen/pembeli kemungkinan besar mempunyai uang lebih untuk belanja online (Amelina dan Zhu, 2016).

Berdasarkan penjelasan tersebut maka hipotesis pertama yang diajukan adalah:

\section{H2: Social Media Instagram berpengaruh positif terhadap Instant Online Buying}

\section{Konsumen}

Kegiatan pemasaran digital umumnya meliputi atau berkisar pada hal-hal yang berhubungan dengan pembuatan produk periklanan, pencarian prospek atau pembelidan penulisan kalimat- kalimat pemasaran.Pemasaran digital ini meliputi kegiatan pembuatan desain web, periklanan dengan mengunakan banner, promosi perusahaan melalui mesin pencari informasi,surat elektronik,pemasaran afiliasi,advertensi interaktif. Perusahaan e-commerce sekarang ini berkembang menggunakan banyak metode pemasaran digital untuk promosi.

Iklan produk yang semakin gencar dan kreatif diera digital berpengaruh terhadap perilaku tingkat persepsi kualitas dan keputusan pembelian konsumen. Reinartz dan Saffert (2013) meneliti tentang pengaruh kreativitas iklan terhadap efektivitas iklan. Sampel yang digunakan adalah iklan televisi yang terdiri dari berbagai produk yang ditayangkan di televisi jerman.

Berdasarkan penjelasan tersebut maka hipotesis kedua yang diajukan adalah

H3: Digital Marketing berpengaruh positif terhadap Instant Online Buying Konsumen 


\section{Gambar 1: Kerangka Pemikiran Teoritis}

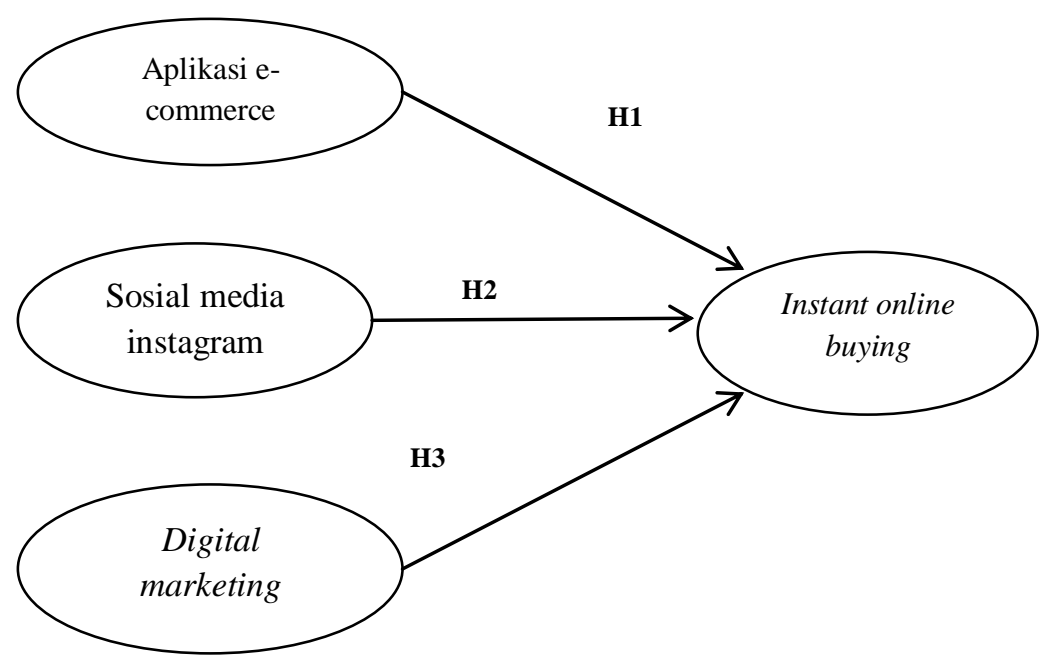

\section{METODE PENELITIAN}

Sumber data primer yang diperlukan dalam penelitian ini diperoleh dengan memberikan kuesioner secara langsung kepada responden. Kriteria yang ditetapkan adalah responden mahasiswa yang sudah pernah belanja online di situs e-commerce yang ada di Indonesia serta mengetahui digital marketing yang digunakan oleh perusahaan pengiklan. Pertimbangan dalam memilih subjek mahasiswa karena mereka tergolong dalam masyarakat menengah, kritis serta mampu memahami pesan-pesan iklan serta mampu memahami produk-produk yang berkaitan dengan sampel iklan tersebut.

Pada masa ini, mereka mulai bersikap kritis terhadap obyek-obyek di luar dirinya, dan mampu mengambil sintesis antara tanggapan tentang dunia luar dengan dunia intern atau kehidupan psikisnya sendiri (Sekaran, 2000). Sehingga diharapkan mampu memahami pertanyaan-pertanyaan yang terdapat dalam kuesioner dan diharapkan mampu memberikan jawaban yang dapat mewakili keadaan sebenarnya.

Penelitian ini mengambil sampel sebanyak 100 orang didasarkan pada pendapat Roscoe bahwa ukuran sampel lebih besar dari 30 dan kurang dari 500 telah mencukupi untuk digunakan dalam semua penelitian (Sekaran, 2000).Metode pengambilan sampel adalah dengan metode non-probability sampling yaitu setiap unsur dalam populasi tidak memiliki kesempatan dan peluang yang sama untuk dipilih sebagai sampel. 
Pengambilan sampel dilakukan dengan purposive sampling yaitu pengambilan sampel dengan kriteria tertentu agar sampel yang diambil sesuai dengan tujuan penelitian.

Analisis data yang dilakukan dengan menggunakan Structural Equation Model (SEM) dengan menggunakan Analysis Moment Structure (AMOS) dalam model dan pengujian hipotesis. SEM atau model persamaan structural adalah sekumpulan teknikteknik statistikal yang memungkinkan pengujian sebuahrangkaian hubungan yang relatif rumit, secara simultan. Yang dimaksud dengan rumit adalah model-model simultan yang dibentuk melalui lebih dari satu variabel dependen pada saat yang sama berperan sebagai variabel independent bagi hubungan berjenjang lainnya.

Sebuah permodelan SEM yang lengkap pada dasarnya terdiri dari dua bagian utama yaitu Measurement Model dan Structural Model. Measurement Model atau model pengukuran untuk mengkonfirmasi indikator-indikator dari sebuah variabel laten serta model struktural yang menggambarkan hubungan kausalitas antar dua atau lebih variabel. Structural Model adalah model mengenai struktur hubungan yang membentuk atau menjelaskan kausalitas antara faktor.

Terdapat tujuh langkah yang harus dilakukan apabila menggunakan permodelan Structural Equation Model (SEM), yaitu pengembangan model berdasar teori, pengembangan diagram alur (path diagram), konversi diagram alur ke dalam persamaan, memilih jenis input matrik dan estimasi model yang diusulkan, menilai problem identifikasi model struktural, menilai kriteria goodness of fit, melakukan interpretasi dan modifikasi model. Dalam penelitian ini, peneliti akan menggunkan SEM untuk melakukan pengujian hipotesis 1-3 diuji dengan path analysis, yaitu untuk mengetahui tingkat signifikansi antar variabel.

\section{HASIL DAN PEMBAHASAN}

Sebanyak 152 responden berpartisipasi dalam penelitian ini. Responden yang berpartisipasi adalah mahasiswa di Yogyakarta. Tingkat respon responden dapat dilihat pada Tabel 1 . 
Tabel 1

Hasil Penyebaran Kuesioner

\begin{tabular}{|c|l|c|}
\hline No. & \multicolumn{1}{|c|}{ Keterangan } & Responden \\
\hline 1. & Kuesioner yang disebar & 160 \\
\hline 2. & Kuesioner yang dikembalikan & 152 \\
\hline 3. & Tingkat respon & $95 \%$ \\
\hline & Total kuesioner yang dianalisis & 152 \\
\hline
\end{tabular}

Analisis demografi digunakan untuk mengetahui demografi profil responden. Dalam penelitian ini, responden diklasifikasikan berdasar pada jenis kelamin, usia (kelahiran 1980-2000). Hasil analisis demografi dirangkum dalam tabel 2 sebagai berikut:

Tabel 2

Profil Responden Berdasarkan Jenis Kelamin

\begin{tabular}{|c|c|c|}
\hline Jenis Kelamin & Jumlah Responden & Persentase \\
\hline Pria & 66 & $43,42 \%$ \\
\hline Wanita & 86 & $56,58 \%$ \\
\hline Total & 152 & $100 \%$ \\
\hline
\end{tabular}

Berdasarkan Tabel 2 diperoleh hasil bahwa responden pria berjumlah 66 orang dengan persentase sebesar $43,42 \%$ dan responden wanita berjumlah 86 orang dengan persentase sebesar $56,58 \%$. Hal ini berarti responden wanita lebih banyak berpartisipasi dalam penelitian ini dibandingkan dengan responden pria.

Uji validitas digunakan untuk mengukur kemampuan skala yang digunakan untuk mengukur konsep yang dimaksud, tujuannya adalah untuk menguji komponen pertanyaan dalam kuesioner dan menjamin bahwa alat ukur yang digunakan cocok dengan objek yang diukur. Factor analysis dinyatakan valid jika Factor Loading > 0.5.

Item pertanyaan pemanfaatan aplikasi e-commere digambarkan dalam EC1 s/d EC6. Nilai factor loading > 0.5 sehingga semua valid. Item pertanyaan sosial media instagram digambarkan dalam IG1 s/d IG7. Nilai factor loading > 0.5 sehingga semua valid. Item pertanyaan digital marketing digambarkan dalam DM1 s/d DM6. Item pertanyaan instant online buying digambarkan dalam OB1 s/d OB7. Nilai factor loading $>0.5$ sehingga semua valid.

Uji reliabilitas digunakan untuk mengetahui sejauh mana hasil pengukuran tetap konsisten jika dilakukan dua kali atau lebih dengan alat ukur yang sama untuk gejala 
yang sama. Suatu kuesioner dikatakan reliabel atau handal jika jawaban seseorang terhadap pertanyaan adalah konsisten atau stabil dari waktu ke waktu. Salah satu cara untuk uji reliabilitas adalah dengan menghitung cronbach's alpha yang menunjukkan konsistensi dalam merespon keseluruhan komponen yang mewakili pengukuran suatu variabel.

Hasil output uji reliabilitas untuk variabel pemanfaatan aplikasi e-commerce, sosial media instagram, instant online buying konsumen generasi milenial dapat diringkas pada Tabel 3 berikut ini.

Tabel 3

Hasil Uji Reliabilitas

\begin{tabular}{|l|c|l|}
\hline \multicolumn{1}{|c|}{ Variabel } & Cronbach alpha & Kategori \\
\hline Aplikasi e-commerce & 0.710 & Reliabilitas baik \\
\hline Sosial media instagram & 0.746 & Reliabilitas baik \\
\hline Digital Marketing & 0.712 & Reliabilitas baik \\
\hline Instant online buying & 0.774 & Reliabilitas baik \\
\hline
\end{tabular}

Statistik deskriptif digunakan untuk menggambarkan variabel variabel yang digunakan dalam penelitian berdasarkan pada kuesioner yang telah dikumpulkan oleh peneliti. Hasil pengujian korelasi antar variabel dalam Tabel 4 tidak ada yang menunjukkan adanya masalah multikolinearitas antar variabel independen, karena nilainya kurang dari 0.8. Hasil pengujian statistik deskriptif dirangkum pada Tabel 4.

Tabel 4

Statistik Deskriptif

\begin{tabular}{|l|c|c|c|c|c|c|}
\hline \multicolumn{1}{|c|}{ Variabel } & Mean & $\begin{array}{c}\text { Std. } \\
\text { Deviasi }\end{array}$ & $\begin{array}{c}\text { Aplikasi } e- \\
\text { commerce }\end{array}$ & $\begin{array}{c}\text { Sosial } \\
\text { media } \\
\text { instagram }\end{array}$ & $\begin{array}{c}\text { Digital } \\
\text { Marketing }\end{array}$ & $\begin{array}{c}\text { Instant } \\
\text { online } \\
\text { buying }\end{array}$ \\
\hline $\begin{array}{l}\text { Aplikasi } e- \\
\text { commerce }\end{array}$ & 3.812 & 0.223 & 1 & $0.309^{* *}$ & $0.442^{* *}$ & $0.630^{* *}$ \\
\hline $\begin{array}{l}\text { Sosial } \\
\text { media } \\
\text { instagram }\end{array}$ & 4.131 & 0.341 & - & 1 & $0.331^{* *}$ & $0.411^{* *}$ \\
\hline $\begin{array}{l}\text { Digital } \\
\text { Marketing }\end{array}$ & 3.362 & 0.412 & - & - & 1 & $0.438^{* *}$ \\
\hline $\begin{array}{l}\text { Instant } \\
\text { online } \\
\text { buying }\end{array}$ & 3.798 & 0.424 & - & - & - & 1 \\
\hline
\end{tabular}

** Menunjukkan korelasi yang signifikan pada tingkat 0.01 
Nilai rata-rata Aplikasi e-commerce sebesar 3.812 menunjukkan bahwa, rata-rata responden menilai aplikasi e-commerce sudah banyak diketahui dan digunakan oleh mahasiswa. Nilai rata-rata Sosial media instagram sebesar 4.131 menunjukkan bahwa, rata-rata responden memiliki sosial media instagram yang digunakan untuk menjadi referensi pembelian online. Nilai rata-rata digital marketing sebesar 3.362 menunjukkan bahwa, rata-rata responden menilai menilai konten iklan digital yang menarik. Terakhir, nilai rata-rata Instant online buying konsumen generasi millenial sebesar 3.798 menunjukkan bahwa, rata-rata responden menilai muncul keputusan pembelian yang tinggi setelah melihat online store.

Nilai GFI (Goodness of Fit) sebesar 0.867. Nilai GFI yang baik adalah yang mendekati angka 1, jadi nilai kesesuaian model dengan data dalam penelitian ini dapat dikatakan cukup baik. Nilai CFI (Comparative Fit Index) sebesar 0.823 Nilai CFI yang baik adalah yang mendekati angka 1 , jadi nilai kesesuaian model dengan data dalam penelitian ini dapat dikatakan cukup baik.

Tabel 5

Hasil Pengujian Model Fit

\begin{tabular}{|c|c|c|c|}
\hline $\begin{array}{c}\text { Goodness-of-fit } \\
\text { Index }\end{array}$ & Kriteria & Hasil Olah Data & Evaluasi Model \\
\hline Chi Square & $\begin{array}{c}\text { Kecil, tidak } \\
\text { signifikan }\end{array}$ & 3.9, Tidak Sig & Baik \\
\hline CMIN/DF & $\begin{array}{c}1-2 \text { over fit, } 2-5 \\
\text { liberal limit }\end{array}$ & 6.218 & Cukup baik \\
\hline GFI & $<1$ & 0.867 & Baik \\
\hline AGFI & $>0,80$ & 0.682 & Cukup Baik \\
\hline TLI & $>0,9$ & 0.738 & Cukup baik \\
\hline CFI & $>0,9$ & 0,823 & Cukup Baik \\
\hline RMSEA & $\begin{array}{c}>0,08 \text { upper limit } \\
0,1\end{array}$ & 0,221 & Kurang baik \\
\hline
\end{tabular}

Nilai GFI (Goodness of Fit) sebesar 0.867 Baik. Nilai TLI (Tucker Lewis Index) sebesar 0.738 cukup baik karena nilainya mendekati 1.Nilai AGFI (Adjusted Goodness of Fit) sebesar 0.682 sedikit memenuhi batas minimum di bawah 0.8. Nilai CMIN/DF berada di atas standar yaitu 6.218, dengan nilai batas maksimal adalah 5. Nilai RMSEA sebesar 0,221 dapat tidak memenuhi kriteria penerimaan model karena melebihi batas atas 0,1 . Oleh karena kriteria pada Goodness of fit index lebih banyak kriteria yang baik 
dan cukup dibandingkan kriteria yang kurang baik, maka secara umum model fit dapat dikatakan cukup baik.

Hipotesis H1, H2, H3, diuji dengan melihat significant path pada penelitian. Hasil pengujian hipotesis dapat terlihat pada Tabel 6.

Tabel 6

Hasil Pengujian Hipotesis

\begin{tabular}{|c|l|c|c|c|}
\hline No & \multicolumn{1}{|c|}{ Isi Hipotesis } & $\begin{array}{c}\text { Standardized } \\
\text { Regression } \\
\text { Weights }\end{array}$ & P & Keterangan \\
\hline H1 & $\begin{array}{l}\text { Pemanfaatan aplikasi } \text { e-commerce } \\
\text { berpengaruh positif terhadap instant } \\
\text { online buying Konsumen generasi } \\
\text { millennial }\end{array}$ & 0.230 & 0.013 & $\begin{array}{c}\text { Hipotesis } \\
\text { diterima }\end{array}$ \\
\hline H2 & $\begin{array}{l}\text { Sosial media instagram berpengaruh } \\
\text { positif terhadap instant online } \\
\text { buying Konsumen generasi millenial }\end{array}$ & 0.629 & $<0.001$ & $\begin{array}{c}\text { Hipotesis } \\
\text { diterima }\end{array}$ \\
\hline H3 & $\begin{array}{l}\text { Digital marketing berpengaruh } \\
\text { positif terhadap instant online } \\
\text { buying Konsumen generasi millenial }\end{array}$ & 0.725 & $<0.001$ & $\begin{array}{c}\text { Hipotesis } \\
\text { diterima }\end{array}$ \\
\hline
\end{tabular}

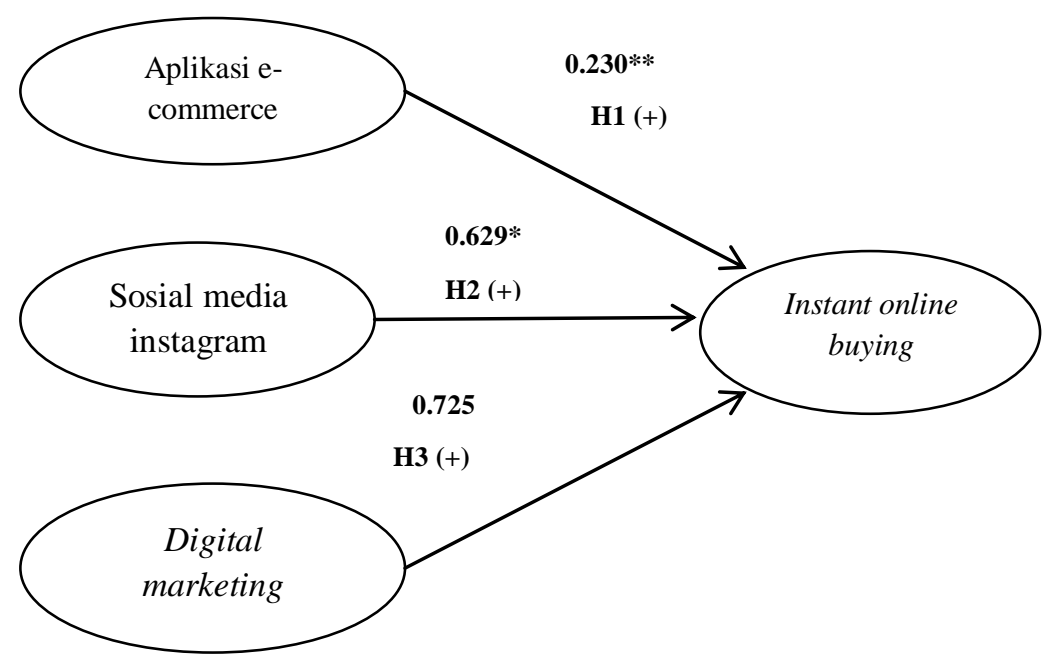

Keterangan: * Signifikan pada $\mathrm{P}<0.05$

** Signifikan pada $\mathrm{P}<0.01$

Pada Tabel 6 ditemukan bahwa aplikasi e-commerce berpengaruh positif terhadap instant online buying konsumen generasi millenial $(\beta=0.230, \mathrm{P}<0,05)$. Hasil analisis ini mendukung hipotesis pertama. Sosial media instagram berpengaruh positif 
terhadap instant online buying konsumen generasi millenial $(\beta=0.629, \mathrm{P}<0.05)$. Hasil analisis ini mendukung hipotesis kedua. Digital marketing berpengaruh positif terhadap instant online buying konsumen generasi millenial $(\beta=0.725, \mathrm{P}<0,1)$. Hasil ini mendukung hipotesis ketiga.

\section{E. SIMPULAN}

Penelitian ini membuktikan adanya pengaruh positifpemanfaatan aplikasi $e$ commerce, sosial media instagram, digital marketing terhadap instant online buying konsumen generasi millenial. Keterbatasan dari penelitian ini adalah jumlah sampel yang masih terbatas, sehingga berpengaruh pada hasil uji statistik yang dilakukan. Selain itu, keterbatasan ruang lingkup sampel yang masih sempit. Penelitian ini hanya mengambil sampel dari latar belakang organisasi pendidikan. Pada penelitian mendatang, perlu ditambahkan sampel dari organisasi dengan latar belakang yang lebih bervariasi agar memperkaya data dan hasil yang dapat diolah.

Beberapa saran penelitian mendatang adalah penambahan jumlah variabel yang dapat melihat model dengan lebih utuh, penambahan variasi latar belakang organisasi, dan menambah jumlah sampel yang mencukupi untuk dapat memenuhi persyaratan dalam penggunaan analisis SEM. Hasil-hasil dari penelitian ini beserta berbagai keterbatasannya agar dapat dijadikan sumber ide dan masukan bagi pengembangan penelitian khususnya yang terkait pada bidang perilaku konsumen dan marketing. Selain itu, dapat dijadikan bahan referensi bagi dunia praktis perusahaan.

\section{DAFTAR PUSTAKA}

Alharethi, M. A. (2016). Using Instagram for shopping in Saudi Arabia (Doctoral dissertation, Arkansas State University).

Amelina, D., \& Zhu, Y. Q. (2016). Investigating Effectiveness of Source Credibility Elements on Social Commerce Endorsement: The Case of Instagram in Indonesia.

Che, J. W., Cheung, C. M., \& Thadani, D. R. (2017, January). Consumer Purchase Decision in Instagram Stores: The Role of Consumer Trust. In Proceedings of the 50th Hawaii International Conference on System Sciences.

Chen, Z., \& Dubinsky, A. J. (2003). A conceptual model of perceived customer value in e-commerce: A preliminary investigation. Psychology \& Marketing, 20(4), 323347. 
Hausman, A. V., \& Siekpe, J. S. (2009). The effect of web interface features on consumer online purchase intentions. Journal of Business Research, 62(1), 5-13.

Huang, Z., \& Benyoucef, M. (2013). From e-commerce to social commerce: A close look at design features. Electronic Commerce Research and Applications, 12(4), 246-259.

Kotler, P., \& Keller, K. L. (2009). Dirección de marketing. Pearson educación.

Laudon, K. J. \& Laudon, J. P. (2012). "Management Information Systems: Managing the Digital Firm", Prentice Hall, Boston, USA, 181.

Maoyan, Zhujunxuan, Sangyang (2014). Consumer Purchase Intention Research Based on Social MediaMarketing, International Journal of Business and Social Science Vol. 5, No. 10(1).

Ramalingam, V., Palaniappan, B., Panchanatham, N and Palanivel, S. 2006. Measuring advertisement effectiveness a neural network approach.Expert Systems with Applications, 31, 159-163.

Reinartz, Werner and Peter Saffert, Peter. 2013. Creativity in Advertising: When It Works and When It Doesn't. Harvard Business Review

Sekaran, U. 2000. Research Methods for Business: A Skill Building Approach, $3^{\text {rd }}$ ed., New York: John Wiley \& Sons, Inc.

Shah, Syed Saad Hussain., Aziz, Jabran., Jaffari, Ahsan raza., Waris, Sidra., Ejaz, Wasiq., Fatima, Maira., Sherazi, Syed Kamran. 2011. The Impact of Brands on Consumer Purchase Intentions. Asian Journal of Business Management 4(2): $105-110$

Taken Smith, K. (2012). Longitudinal study of digital marketing strategies targeting Millennials. Journal of Consumer Marketing, 29(2), 86-92.

Tarasova, E. (2015, June). Instagraming in Russia. In 2015 Global Fashion Management Conference at Florence (pp. 187-188).

Tiago, M. T. P. M. B., \& Veríssimo, J. M. C. (2014). Digital marketing and social media: Why bother?. Business Horizons, 57(6), 703-708.

Zadmehr, S., Fatourehchi, S., \& Zadmehr, H. (2016). Identifying and Structuring Factors

Affecting the Purchase from Mobile Social Networks (Case Study: Instagram Application). International Journal of Life Sciences, 10(2), e115-e127.

Zeithaml, Valarie A. Mry Jo Bitner. (2002). Services Marketing: Integrating Customer Focus Across The Firm, Second Edition Hill. . New York: McGraw 